\title{
TRENDS IN HEALTH FACILITY DELIVERIES AND CAESAREAN SECTIONS BY WEALTH QUINTILE IN MOROCCO BETWEEN 1987 AND 2012
}

Jenny A. Cresswell *1, Bouchra Assarag ${ }^{2}$, Fatima-Zahra Meski ${ }^{2}$, Veronique Filippi ${ }^{1}$, Carine Ronsmans ${ }^{1}$

\footnotetext{
${ }^{1}$ London School of Hygiene \& Tropical Medicine, London, UK.

${ }^{2}$ Ecole Nationale de santé publique, Rabat, Morocco
}

*Corresponding author: London School of Hygiene \& Tropical Medicine, Keppel Street, London, UK. WC1E 7HT. Jenny.Cresswell@Ishtm.ac.uk

WORD COUNT:

Abstract: 250

Main text: 3299 


\section{ABSTRACT}

OBJECTIVES: To examine trends in the utilisation of facility-based delivery care and caesareans in Morocco between 1987 and 2012, particularly among the poor. We also assess whether uptake increased the time of introduction of policies or programmes aimed at improving access to intrapartum care.

METHODS: We used two sources of data: nationally-representative household surveys and routine statistics. Our analysis focused on whether women delivered within a facility, and whether the delivery was by caesarean; analyses were stratified by relative wealth quintile and public/private sector where possible. A segmented Poisson regression model was used to assess whether trends changed at key events.

RESULTS: Uptake of facility-based deliveries and caesareans in Morocco has risen considerably over the past two decades; particularly among the poor. The rate of increase in facility deliveries was much faster in the poorest quintile (annual increase RR: 1.09; 95\% Cl: 1.07-1.11) compared to the richest quintile (annual increase RR: 1.01; 95\% Cl: 1.02-1.02). A similar pattern was observed for caesareans (annual increase among poorest RR: $1.13 ; 95 \% \mathrm{Cl}$ : $1.07-1.19$ vs. annual increase among richest RR: $1.08 ; 95 \% \mathrm{Cl}: 1.06-1.10)$. We found no significant acceleration in trend coinciding with any of the events investigated.

CONCLUSIONS: Morocco's success in improving uptake of facility deliveries and caesareans is likely to be the result of the synergistic effects of comprehensive demand and supply side strategies, including a major investment in human resources and free delivery care. Continuing challenges in equity still need to be addressed; however the overall trend is positive. 


\section{INTRODUCTION}

Healthcare during the intrapartum period is regarded as the optimal strategy to reduce maternal and perinatal mortality [1]. Most effective evidence-based interventions require deliveries to take place in a well-equipped facility capable of providing at least basic emergency obstetric care, with the means for prompt referral to higher-level facilities capable of providing comprehensive emergency obstetric care, including caesareans [2]. A number of governments in low- and middle- income countries have introduced various strategies to improve timely access to delivery care in health facilities, including increasing the number of trained healthcare providers and the removal of financial barriers through insurance or exemption of user fees [3-5]. How these various strategies impact on uptake of health facility deliveries and caesarean sections is not well known however, particularly among the poor.

Morocco, a lower-middle income country with a total population of 32.5 million in 2012 [6], has shown strong political commitment to improve intrapartum care [7]. Maternal mortality has fallen dramatically, though estimates of the magnitude of the decline vary depending on source. According to the World Health Organization, maternal mortality has declined from 310 deaths per 100,000 live births in 1990 to 120 in 2013 , while the Global Burden of Disease study gives figures of 280 and 64 deaths per 100,000 live births for 1990 and 2013 respectively $[8,9]$. Whichever set of estimates are used, the improvements in maternal mortality are impressive, and understanding how this happened is important.

Over the past two decades, Morocco introduced a number of comprehensive strategies directed both at the supply of and demand for quality obstetric care in health facilities. On the supply side, Morocco reformed the training of nurse-midwives with the introduction of a three year undergraduate programme in 1993 [10] and further strengthened Morocco's maternal mortality prevention strategy through improving emergency obstetric care and increasing public awareness of the problem under the Family Planning/Maternal and Child Health Phase V Project in 1994 [11].On the demand side, the government legislated plans in 2002 to phase in universal health care coverage [12], including a mandatory health insurance for public and formal-private sector employees (I'Assurance Maladie Obligatoire; AMO) and a fund to provide free health insurance to the poorest households, with the less poor able to purchase subsidised insurance on a sliding scale (Regime d'Assistance Medicale; RAMED) $[13,14]$. Implementation of the mandatory health insurance began in 2005; 
and the health insurance for the poor was piloted in one province in 2008 but national implementation did not occur until 2011 [15].

In December 2007, the Ministry of Health made maternal and neonatal health a priority in its Action Plan 2008-12. It launched a Commission to Reduce Maternal Mortality in January 2008 which set out an Action Plan to reduce physical and financial barriers to emergency obstetric care, improve quality of care through audits and upgrades of delivery facilities and improve governance [7]. From December 2008, a policy to remove delivery fees in public hospitals was launched, including an exemption for vaginal or caesarean delivery fees, hospital stay, essential medicines, examinations including laboratory and ultrasound, and referral transport [16]. Delivery care within public facilities in Morocco should now be provided free of charge, although in practice many households still pay substantial extra costs for medicines and transport [17]. Under the Action Plan, a national maternal mortality surveillance system was also put in place to monitor progress [7].

The objective of this study is to examine whether and how the various strategies to improve demand and supply for better maternal health care have increased trends in the utilisation of facility-based delivery care and caesarean sections between 1987 and 2012, particularly among the poor. We also examine whether uptake of facility deliveries and caesareans accelerated at the time of major changes in policy; including 1994 (the Family Planning/Maternal and Child Health Phase V Project); 2005-2006 (the introduction of health insurance programmes); and 2008 (the Action Plan to Reduce Maternal Mortality).

\section{METHODS}

We used two sources of data: nationally-representative household surveys and routine statistics. For the survey-based analysis we used data from the 1992 and 2003-04 Morocco Demographic and Health Surveys (DHS) available at www.dhsprogram.com, and the 2011 National Population and Family Health Survey (ENPSF)

[18-20] made available by the Ministry of Health. Routine data on the annual number of deliveries and caesareans in public facilities and the total number of births nationally were extracted from the "Santé en chiffres" reports from 1992 to 2012, published by the Ministry of Health and available at 
http://srvweb.sante.gov.ma . These reports do not record private sector deliveries. National GDP per capita (in current US \$) was obtained from the World Bank [6].

\section{Survey-based analysis:}

The three survey-based datasets were combined to provide delivery-based trends in obstetric care over the period 1987- 2010 (no data were available for 1992-1997). The response rate across each of these surveys was $94 \%$ or greater. In cases where a delivery resulted in a multiple birth, the place and mode of delivery was defined as that of the latest-born infant. The DHS collected information relating to all live births in the five years preceding the survey; the ENPSF collected information only on the most recent live birth in the five years preceding the survey.

Our analysis focused on whether women delivered within a health facility and by caesarean. Health facilities were separated into private (including a private hospital or clinic) and public facilities (government hospital, health centre/maison d'accouchement). The DHS wealth index, a composite index of household assets at the time of each survey with households categorised into quintiles was used as a measure of relative wealth[21]. Data were also presented stratified by region. Poisson regression was used to calculate annual trends in facility deliveries and caesareans from 1987 to 2010, testing for interaction between time and relative wealth quintile using the Wald test. All survey-based analyses took the complex survey design (sample weights, clustering and stratification) into account.

\section{Analysis of the routine data:}

Population-based facility delivery rates and caesarean rates were calculated from the routine data as a ratio of total expected births. Trends over time were assessed between 1992 and 2012 by fitting a segmented Poisson regression model to calculate annual relative risks (RRs) along with 95\% confidence intervals (Cls) [22]. Random effects were fitted to allow for correlation of standard errors. We described trends between the start of the Morocco Family Planning/Maternal and Child Health Phase V in 1994 and the implementation of mandatory health insurance in 2005; between the implementation of mandatory insurance in 2005 and the start of the Action Plan to Reduce Maternal Mortality in 2008; and from the introduction of the Action Plan in 2008 to 2012. Our model allowed us to test the statistical significance of any change in trend between these periods. 
All analyses were carried out using Stata 13.

\section{RESULTS}

Trends over time in the percent of deliveries in a health facility and by caesarean using survey data are shown

in Table 1. Percents are not presented for years with fewer than 100 deliveries because of the imprecision of the estimates. The percent of deliveries in any health facility increased steadily from $24.9 \%$ in 1987 to $74.1 \%$ in 2010 (annual increase RR: 1.05; 95\% Cl: 1.04-1.05). Overall caesarean rates increased from $1.9 \%$ in 1987 to 9.6\% in 2010 (annual increase RR: 1.10; 95\% Cl: 1.09-1.12). Facility deliveries mostly took place in the public sector: by $2010,89 \%$ of all deliveries in health facilities continued to be in the public sector. However, an increasing share of caesareans took place within the private sector; by $201039 \%$ of all caesareans were in the private sector, compared to $19 \%$ in 1987 . Estimates of the percent of deliveries and caesareans within a public facility obtained from the routine statistics are reasonably consistent with estimates obtained from survey data (Figure 1 and Figure 2).

Trends in facility deliveries and caesarean sections by relative wealth are shown in Table 2, Figure 3 and Figure 4. Facility deliveries increased across all wealth groups over the 23-year period, although substantial variation in the percent delivering within a facility by wealth quintile remains. There was a statistically significant interaction between time and relative wealth quintile $(F=53.77 ; p<0.0001)$ with a higher rate of increase among the poorest. Among women from the poorest $20 \%$ of households, facility-based deliveries increased from the late 1990s onwards: by the most recent survey $37.7 \%$ delivered in a health facility. Among the richest $20 \%$, facility deliveries were near universal by 2000 (93.8\%). The rate of increase was fastest in the poorest quintile (annual increase RR: $1.09 ; 95 \% \mathrm{Cl}$ : 1.07-1.11) compared to the richest quintile (annual increase RR: $1.01 ; 95 \% \mathrm{Cl}: 1.02-1.02$ ). The rise in facility deliveries among the richest $20 \%$ was mainly due to an increase in private sector deliveries (Figure 3).

Caesarean delivery rates increased across all wealth groups. Similar to facility-based deliveries, there was a significant interaction between time and relative wealth quintile $(F=2.91 ; p=0.0207)$. Among women from the poorest $20 \%$ of households, only $0.3 \%$ delivered by caesarean in $1987-1991$; by the most recent survey 
(covering $2005-2010$ ) this had risen to $3.7 \%$. Among the richest $20 \%$, the caesarean rate had reached $27 \%$ by the most recent survey, and most caesareans in this group took place in the private sector. The rate of increase was fastest in the poorest quintile (annual increase RR: 1.13 ; 95\% Cl: 1.07-1.19) compared to the richest quintile (annual increase RR: $1.08 ; 95 \% \mathrm{Cl}: 1.06-1.10$ ).

Currently regional facility delivery rates vary from $57.3 \%$ in Taza-Al Hoceima-Taounate to $91.1 \%$ in Rabat-SaléZemmour-Zair (Figure 5). There has been substantial increases in caesarean delivery rates across all regions. The caesarean delivery rate in Grand Casablanca is currently very high (30.1\%); across other regions caesarean delivery rates range from $6.8 \%$ in El Gharb-Chrarda Bni Hssen to $14.1 \%$ in Oriental.

Figure 6 presents the results of the segmented regression investigating change in utilisation trends at three important policies for delivery care using routine statistics. We found no evidence that any of the policies considered in this study significantly accelerated trends in utilisation of obstetric care above the underlying secular trend, which was positive (overall annual $R R=1.04(95 \% \mathrm{Cl}: 1.03-1.05)$ for facility deliveries and annual overall $\mathrm{RR}=1.11(95 \% \mathrm{Cl}: 1.06-1.16)$ for caesarean sections)

\section{DISCUSSION}

Our study shows that uptake of facility-based delivery care and caesarean sections in Morocco has risen considerably over the past two decades, with the poorest households experiencing the fastest rate of increase. In 1987 , just $25 \%$ of deliveries took place within a health facility compared to over $70 \%$ in 2010 , most of which took place in the public sector. In 1987, the overall caesarean rate was just under $2 \%$; by 2010 it had increased to $13 \%$ with an increasing proportion performed in the private sector. The equity gap between the richest and poorest has narrowed considerably since the 1990s, though inequality in the utilisation of obstetric services persists. In the most recent survey, women from the richest $20 \%$ of households were more than twice as likely to make use of facility-based delivery care and nearly three times more likely to deliver by caesarean section as those women from the poorest $20 \%$ of households.

The dramatic increase in facility-based delivery care and caesarean sections is likely to be multi-factorial. We found no evidence of acceleration in trend coinciding with any of the policies or programmes investigated; but this is perhaps not surprising. Each programme was complementary, addressing both demand and supply side 
barriers to care, and acted synergistically to improve utilisation of facility care. Supply side interventions have resulted in a dramatic increase in human resources for delivery care. For example, the number of doctors in the public sector increased from 3,779 in 1992 to 11,812 in 2012; whilst the number of doctors in the private sector also increased from 3,324 in 1992 to 7,934 in 2012 [23, 24]. Data on the number of midwives are not easily available but the 2014 State of the World Midwifery report estimates that in 2012 Morocco had 3,059 midwives or nurse-midwives [25]. This, together with the removal of financial barriers and efforts to increase the quality of care through audit and surveillance will no doubt have contributed to Morocco's success in increasing access to facility-based delivery care. Morocco has also experienced substantial economic and demographic changes over this period: GDP per capita has increased from US $\$ 1,037$ in 1990 to US $\$ 2,902$ in 2012, whilst average fertility has declined from a total fertility rate of 4.1 births per woman in 1990 to 2.7 births per woman in 2012[6]. Adult female literacy has increased from 29\% in 1994 to $58 \%$ in 2011, although a substantial minority of women still have low levels of education [6].

The dramatic rise in facility deliveries and caesarean sections among the poor is impressive, even though further improvements could be achieved. The poorest women tend to be the least educated $(85 \%$ of the poorest quintile in 2011 were uneducated) and live in the most remote parts of Morocco, with long distances to health facilities and poor transport systems. Strengthening the availability of qualified medical staff in remote areas, and further improving emergency transport and referral links needs to remain a priority.

Although the optimal caesarean rate remains a matter of debate, a rate of $28 \%$ among the richest is likely to reflect a substantial number of medically-unnecessary caesarean sections [26]. Caesareans have been shown to increase the risk of maternal and neonatal morbidity and mortality [27], and they substantially increase the cost of care. The excess in caesarean sections was seen almost exclusively among the $20 \%$ wealthiest women, most of whom live in urban areas, such as Grand Casablanca, where private care tends to be concentrated. $36 \%$ of deliveries in the private sector were by caesarean, compared to $8 \%$ in the public sector (data not shown). Similar patterns have been reported in many other countries, and are thought to be due to a greater involvement of doctors relative to midwives in the private sector, financial incentives favoring caesarean sections, and incorrect beliefs that caesareans represent better quality care [28]. 
A particular strength of this study was the availability of data from both routine statistics and nationally representative population-based surveys over a long period. Reassuringly, the routine statistics and survey data gave consistent estimates for uptake of facility-based deliveries and caesarean sections in public health facilities. One of the added advantages of survey data is that trends can be deconstructed by public-private sector deliveries and by relative household wealth. Our study has some limitations however. We did not have survey-based data for a five year period between 1992 and 1997, so are unable to present disaggregated trends during this period. We used the routine data for our trend analysis because we had complete information for a twenty-year period, but this meant that we could not disaggregate the model by relative wealth or other socio-demographic variables. The wealth quintiles describe comparative wealth of households at the time of a particular survey and the absolute level of wealth within any given quintile will vary over time. Lastly, survey-based information on place and mode of delivery was subject to maternal recall though this bias is likely to be small as indicated by the consistency with the routine data.

Our study illustrates the difficulties in evaluating the contribution of specific policies on uptake of care when programmes are implemented incrementally over time at national level. For example, although there is some evidence that removal of user fees can be an effective strategy to increase utilisation of maternity health services [29], there was no evidence of any increase additional to the existing secular trend in Morocco. In Morocco, as is probably the case in most countries, the implementation of the fee exemption policy came shortly after a number of other important changes to the health system; each of which may have had a complementary and mutually re-enforcing effect that cannot be separated out. There were only a few years between the introduction of many of the policies, and delays in roll-out and implementation precluded us from distinguishing the individual effects. Most importantly, the health insurance and fee exemption policies were introduced after major investments in the resources available for maternity care [25]. Though regional differentials in access to health care and substandard care in health facilities persist [30], it is clear that the comprehensive demand and supply strategy has led to major gains in utilisation of obstetric care and reductions in maternal mortality in Morocco over the past two decades.

Morocco has demonstrated a strong political will to improve maternal and perinatal health, which is reflected in the trends in utilisation of facility-based delivery care over the past twenty-five years. Challenges remain to be addressed, such as the relatively low rates of utilisation persisting among the poorest, however the overall 
trend is a positive one. Morocco has demonstrated strong commitment to reducing financial barriers to obstetric care; future interventions may want to look at issues of geographic accessibility and quality of care within facilities.

\section{ACKNOWLEDGMENTS}

The authors would like to thank Vincent De Brouwere for his helpful comments on a draft of this paper. We thank the Morocco Ministry of Health for making the data from the 2011 National Population and Family Health Survey (ENPSF) available to us. This work was carried out as part of the FEMHealth project (PI: Dr Sophie Witter); we would like to thank the rest of the FEMHealth partners for productive discussions and feedback during presentations and meetings (see www.abdn.ac.uk/femhealth). FEMHealth was funded by the European Union.

\section{ETHICAL ISSUES}

This study utilized anonymized secondary survey data and routine statistics that are publically available, with the exception of the 2011 National Population and Family Health Survey. Approval to use the latter data was granted by the Direction de la Planification et des Ressources Financières in the Ministry of Health [Ref: 144/DPRF/10]. The protocol was approved by the London School of Hygiene \& Tropical Medicine Institutional Review Board [Ref: 6103/A453]. 


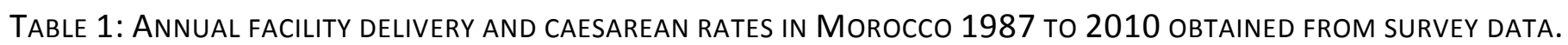

\begin{tabular}{|c|c|c|c|c|c|c|c|c|c|c|}
\hline \multirow[b]{2}{*}{$\begin{array}{l}\text { Survey } \\
\text { (Year of } \\
\text { Survey) }\end{array}$} & \multirow[b]{2}{*}{$\begin{array}{l}\text { Year of } \\
\text { Delivery }\end{array}$} & \multirow[b]{2}{*}{$\mathbf{N}$} & \multicolumn{4}{|c|}{ Facility-based delivery } & \multicolumn{4}{|c|}{ Caesarean sections } \\
\hline & & & $\begin{array}{l}\text { Missing } \\
\text { Values }\end{array}$ & Overall \% & $\begin{array}{l}\text { Percent in } \\
\text { Public } \\
\text { Facilities }\end{array}$ & $\begin{array}{l}\text { Percent in } \\
\text { Private } \\
\text { Facilities }\end{array}$ & $\begin{array}{l}\text { Missing } \\
\text { Values }\end{array}$ & Overall \% & $\begin{array}{l}\text { Percent in } \\
\text { Public } \\
\text { Facilities }\end{array}$ & $\begin{array}{l}\text { Percent in } \\
\text { Private } \\
\text { Facilities }\end{array}$ \\
\hline \multirow{6}{*}{$\begin{array}{l}\text { DHS II } \\
(1992)\end{array}$} & 1987 & 822 & 0 & $24.9 \%$ & $87 \%$ & $13 \%$ & 0 & $1.9 \%$ & $81 \%$ & $19 \%$ \\
\hline & 1988 & 1,057 & 3 & $27.4 \%$ & $87 \%$ & $14 \%$ & 3 & $1.3 \%$ & $93 \%$ & $7 \%$ \\
\hline & 1989 & 976 & 1 & $27.5 \%$ & $86 \%$ & $14 \%$ & 0 & $1.4 \%$ & $50 \%$ & $50 \%$ \\
\hline & 1990 & 1,057 & 2 & $27.8 \%$ & $85 \%$ & $15 \%$ & 0 & $1.6 \%$ & $82 \%$ & $18 \%$ \\
\hline & 1991 & 1,008 & 0 & $34.5 \%$ & $87 \%$ & $13 \%$ & 0 & $2.3 \%$ & $74 \%$ & $26 \%$ \\
\hline & 1992 & 0 & & & & & & & & \\
\hline \multirow{5}{*}{ None } & 1993 & 0 & & & & & & & & \\
\hline & 1994 & 0 & & & & & & & & \\
\hline & 1995 & 0 & & & & & & & & \\
\hline & 1996 & 0 & & & & & & & & \\
\hline & 1997 & 0 & & & & & & & & \\
\hline \multirow{7}{*}{$\begin{array}{l}\text { DHS IV } \\
(2003-04)\end{array}$} & 1998 & 21 & 1 & $\infty$ & $\infty$ & $\infty$ & 0 & $\infty$ & $\infty$ & $\infty$ \\
\hline & 1999 & 1,195 & 8 & $57.8 \%$ & $84 \%$ & $16 \%$ & 12 & $4.4 \%$ & $48 \%$ & $52 \%$ \\
\hline & 2000 & 1,286 & 14 & $58.2 \%$ & $87 \%$ & $13 \%$ & 10 & $5.3 \%$ & $55 \%$ & $45 \%$ \\
\hline & 2001 & 1,154 & 3 & $61.8 \%$ & $90 \%$ & $10 \%$ & 8 & $5.4 \%$ & $59 \%$ & $41 \%$ \\
\hline & 2002 & 1,165 & 7 & $63.2 \%$ & $88 \%$ & $12 \%$ & 18 & $5.9 \%$ & $57 \%$ & $43 \%$ \\
\hline & 2003 & 876 & 5 & $65.7 \%$ & $87 \%$ & $13 \%$ & 5 & $6.3 \%$ & $56 \%$ & $44 \%$ \\
\hline & 2004 & 0 & & & & & & & & \\
\hline \multirow{6}{*}{$\begin{array}{l}\text { ENPSF } \\
(2011)\end{array}$} & 2005 & 13 & 0 & $\infty$ & $\infty$ & $\infty$ & 0 & $\infty$ & $\infty$ & $\infty$ \\
\hline & 2006 & 653 & 5 & $73.4 \%$ & $88 \%$ & $12 \%$ & 5 & $12.1 \%$ & $55 \%$ & $45 \%$ \\
\hline & 2007 & 878 & 1 & $72.4 \%$ & $88 \%$ & $12 \%$ & 1 & $11.4 \%$ & $58 \%$ & $42 \%$ \\
\hline & 2008 & 1,170 & 4 & $72.2 \%$ & $86 \%$ & $14 \%$ & 4 & $13.9 \%$ & $66 \%$ & $34 \%$ \\
\hline & 2009 & 1,408 & 12 & $73.4 \%$ & $87 \%$ & $13 \%$ & 12 & $12.6 \%$ & $63 \%$ & $37 \%$ \\
\hline & 2010 & 1,182 & 8 & $74.1 \%$ & $89 \%$ & $11 \%$ & 8 & $9.6 \%$ & $61 \%$ & $39 \%$ \\
\hline \multicolumn{2}{|c|}{$\begin{array}{l}\text { Annual Trend } 1987 \text { to } 2010 \\
\text { Risk Ratio }[95 \% \mathrm{Cl}]\end{array}$} & 15,921 & 74 & \multicolumn{3}{|c|}{$1.05[1.04,1.05]$} & 87 & \multicolumn{3}{|c|}{$1.10[1.09,1.12]$} \\
\hline
\end{tabular}

$\infty$ Data not presented for years with fewer than 100 deliveries. 
Figure 1: PeRcent of Deliveries taking PLACE Within A PUblic health FACILITY BetWeen 1987 AND 2012 (COMPARISON OF SURVEY DATA AND ROUTINE STATISTICS).

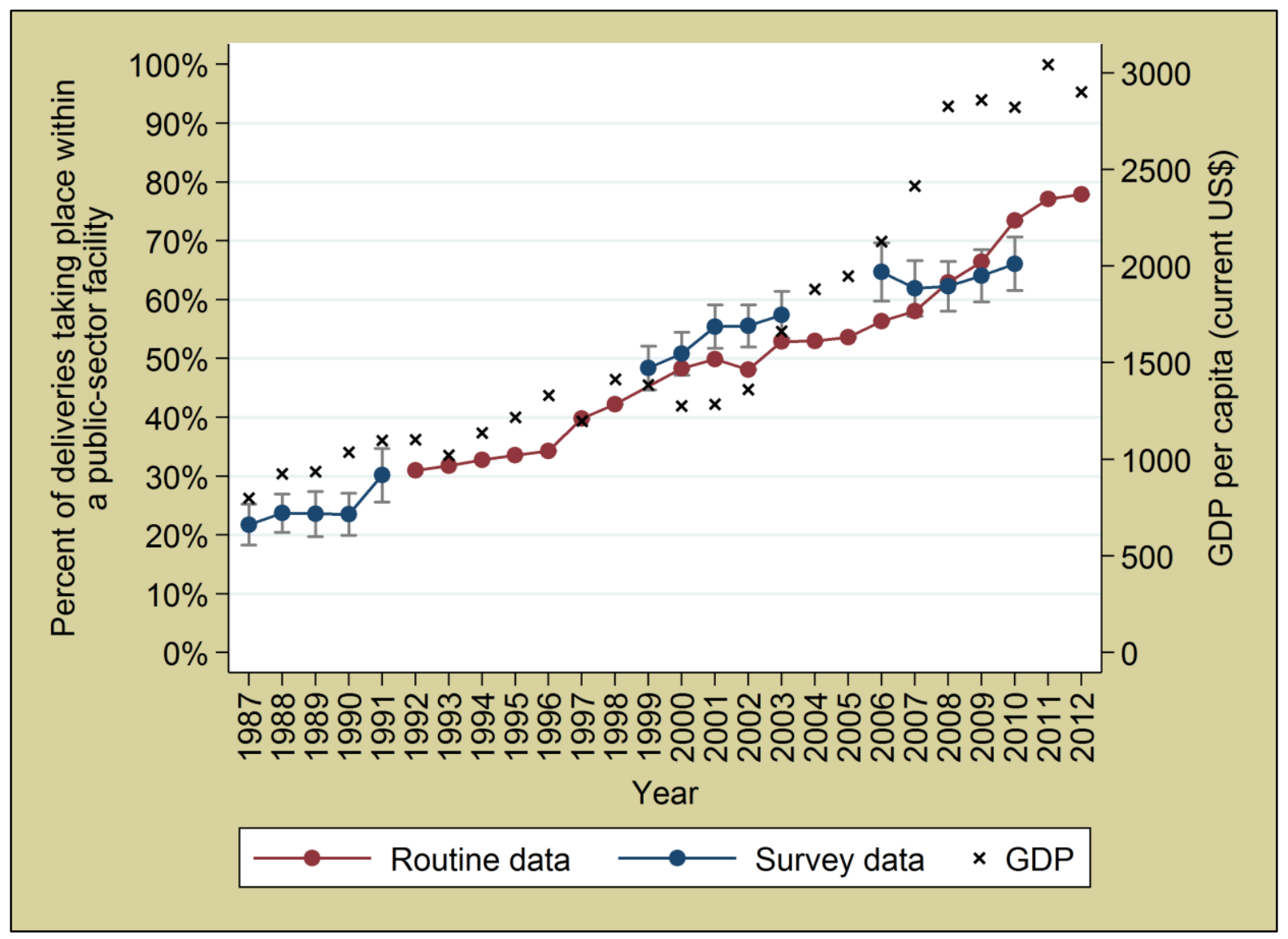




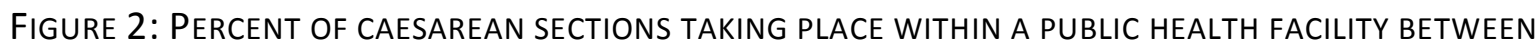
1987 AND 2012 (COMPARISON OF SURVEY DATA AND ROUTINE STATISTICS).

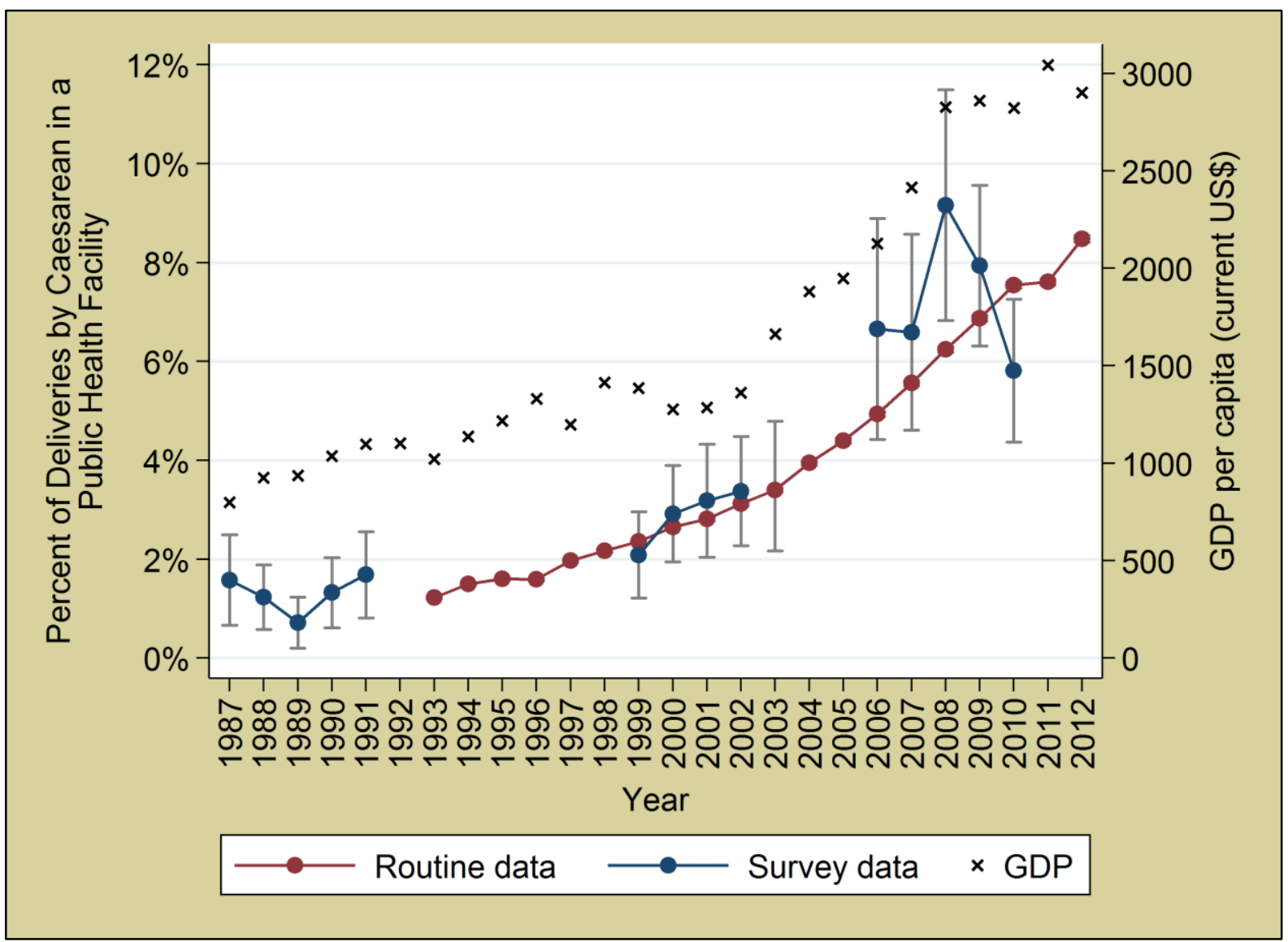


TABLE 2: EQUITY IN FACILITY DELIVERY AND CAESAREAN RATES IN Morocco 1987 to 2010.

\begin{tabular}{|c|c|c|c|c|c|c|c|}
\hline \multirow{2}{*}{$\begin{array}{l}\text { Relative } \\
\text { Wealth } \\
\text { Quintile }\end{array}$} & \multirow{2}{*}{$\begin{array}{c}\text { Annual Trend } \\
1987 \text { to } 2010 \\
\text { RR }[95 \% \mathrm{Cl}]\end{array}$} & \multicolumn{2}{|c|}{$\begin{array}{c}\text { DHS-II } \\
\text { [1987 to 1991] }\end{array}$} & \multicolumn{2}{|c|}{$\begin{array}{c}\text { DHS-IV } \\
\text { [1998 to 2003] }\end{array}$} & \multicolumn{2}{|c|}{$\begin{array}{c}\text { ENPSF } \\
\text { [2005 to 2010] }\end{array}$} \\
\hline & & Percent (\%) & $\operatorname{RR}[95 \% \mathrm{Cl}]$ & Percent (\%) & $\operatorname{RR}[95 \% \mathrm{Cl}]$ & Percent (\%) & $\operatorname{RR}[95 \% \mathrm{Cl}]$ \\
\hline \multicolumn{8}{|c|}{ Health facility delivery: } \\
\hline Poorest & $1.09[1.07,1.11]$ & $5.0 \%$ & 1.00 & $28.0 \%$ & 1.00 & $37.7 \%$ & 1.00 \\
\hline Poorer & $1.08[1.07,1.09]$ & $13.0 \%$ & $2.59[1.74,3.86]$ & $47.8 \%$ & $1.71[1.44,2.02]$ & $61.1 \%$ & $1.78[1.54,2.06]$ \\
\hline Middle & $1.06[1.05,1.07]$ & $26.6 \%$ & $5.28[3.58,7.87]$ & $67.9 \%$ & $2.43[2.05,2.88]$ & $86.2 \%$ & $2.29[1.95,2.68]$ \\
\hline Richer & $1.03[1.02,1.04]$ & $49.4 \%$ & $9.82[6.63,14.54]$ & $83.6 \%$ & $2.99[2.54,3.51]$ & $89.9 \%$ & $2.39[2.03,2.80]$ \\
\hline Richest & $1.01[1.01,1.02]$ & $70.8 \%$ & $14.08[9.71,20.40]$ & $93.9 \%$ & $3.36[2.87,3.93]$ & $93.8 \%$ & $2.49[2.13,2.91]$ \\
\hline \multicolumn{8}{|c|}{ Caesarean delivery: } \\
\hline Poorest & $1.13[1.07,1.19]$ & $0.3 \%$ & 1.00 & $1.5 \%$ & 1.00 & $3.7 \%$ & 1.00 \\
\hline Poorer & $1.13[1.09,1.17]$ & $0.6 \%$ & $1.91[0.35,10.59]$ & $1.8 \%$ & $1.21[0.65,2.25]$ & $6.5 \%$ & $1.76[1.16,2.65]$ \\
\hline Middle & $1.15[1.10,1.19]$ & $0.8 \%$ & $2.44[0.42,14.05]$ & $3.4 \%$ & $2.34[1.29,4.24]$ & $10.9 \%$ & $2.95[2.02,4.33]$ \\
\hline Richer & $1.09[1.06,1.12]$ & $2.7 \%$ & $8.22[1.65,40.84]$ & $7.8 \%$ & $5.32[3.08,9.18]$ & $15.8 \%$ & $4.26[2.96,6.13]$ \\
\hline Richest & $1.08[1.06,1.10]$ & $5.8 \%$ & $17.80[3.74,84.74]$ & $16.0 \%$ & $10.97[6.60,18.21]$ & $27.0 \%$ & $7.29[5.08,10.47]$ \\
\hline
\end{tabular}


FIGURE 3: TRENDS IN FACILITY DELIVERY BY PUBLIC/PRIVATE SECTOR, STRATIFIED BY RELATIVE WEALTH. [WQ=WEALTH QUINTILE]

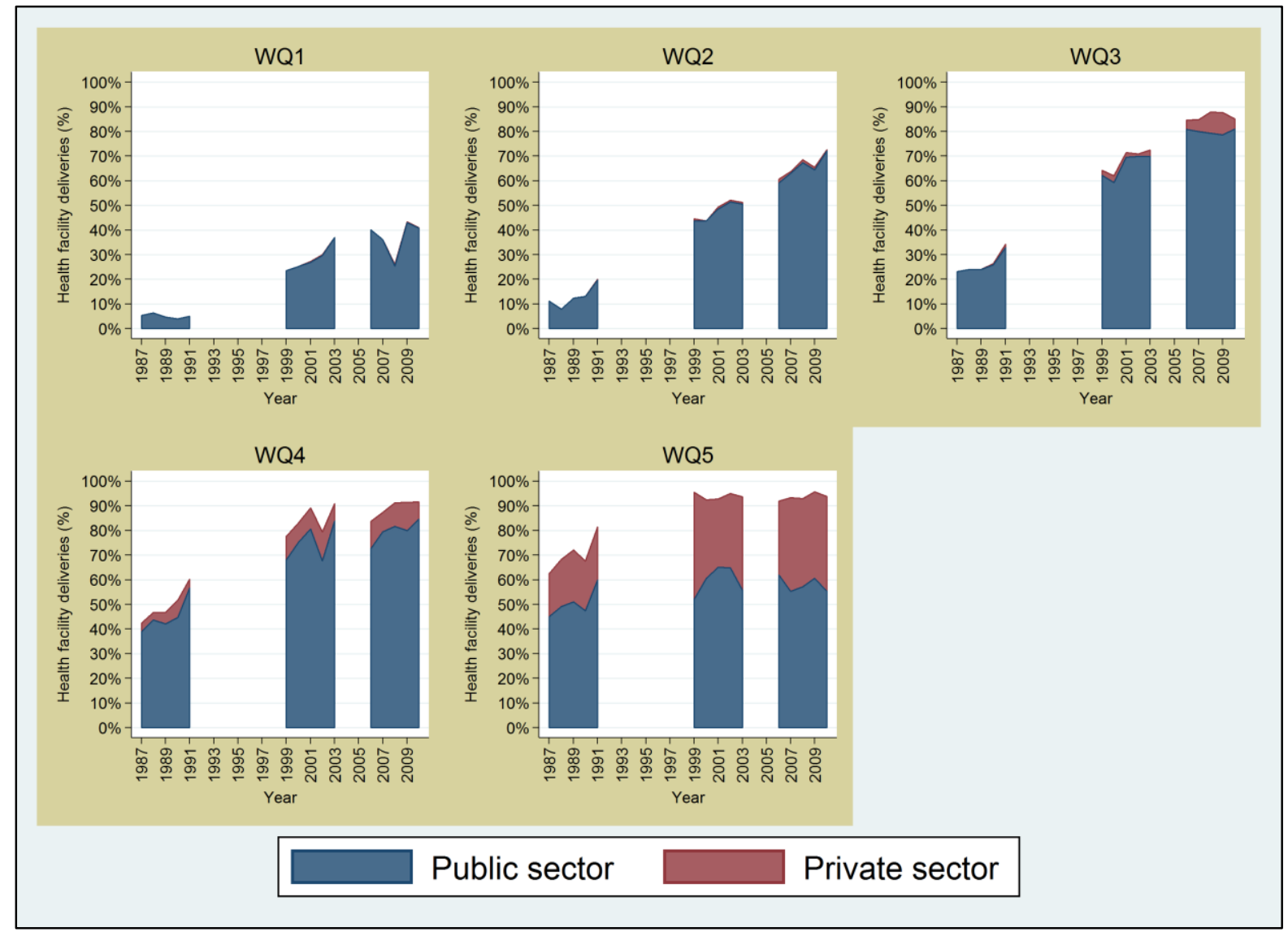


Figure 4: TRENDS IN CAESAREAN SECTIONS BY PUBLIC/PRIVATE SECTOR, STRATIFIED BY RELATIVE WEALTH. [WQ=WEALTH QUINTILE]

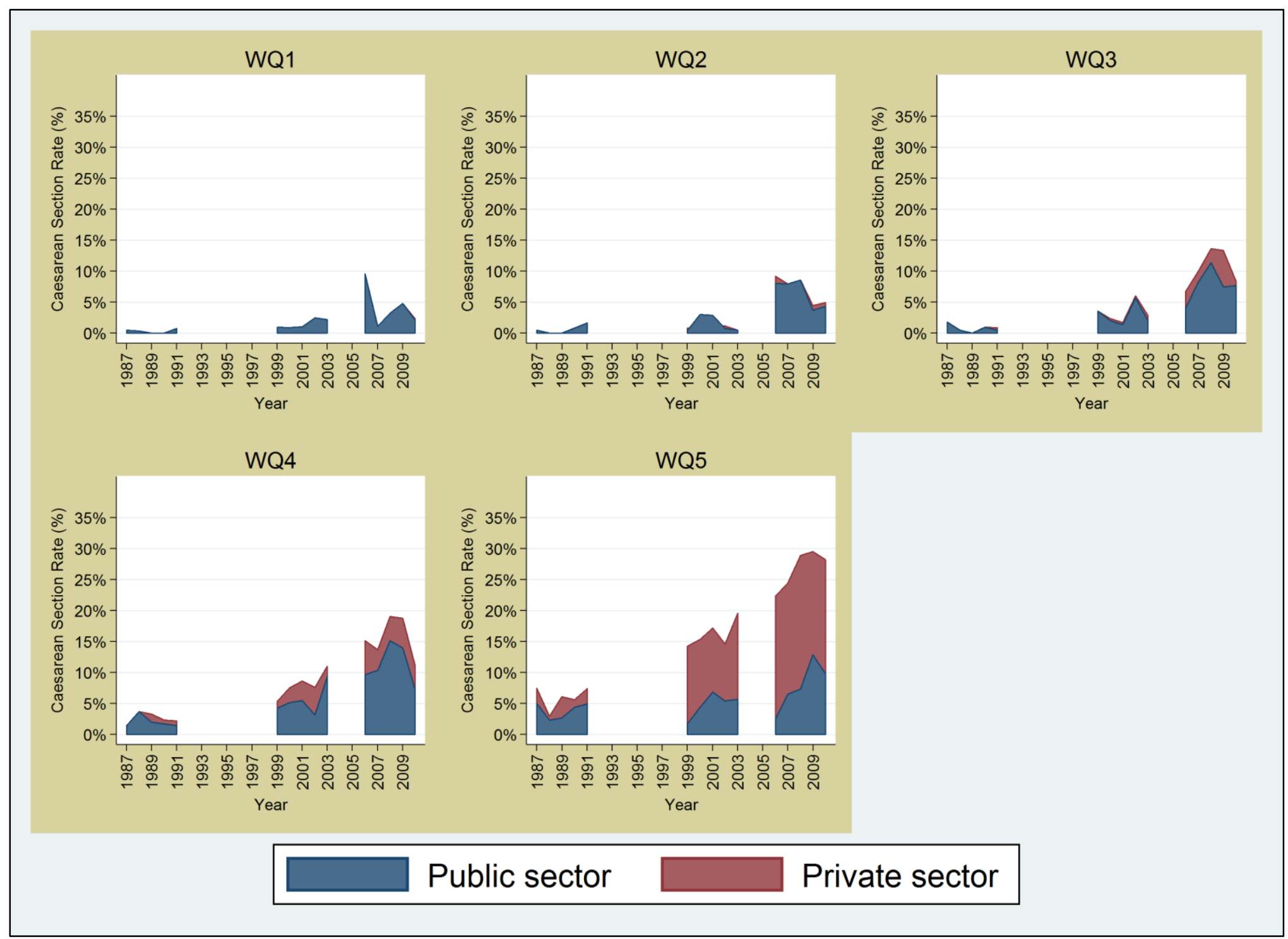

Page | 16 
FIGURE 5: REGIONAL VARIATION IN FACILITY DELIVERY AND CAESAREAN DELIVERY

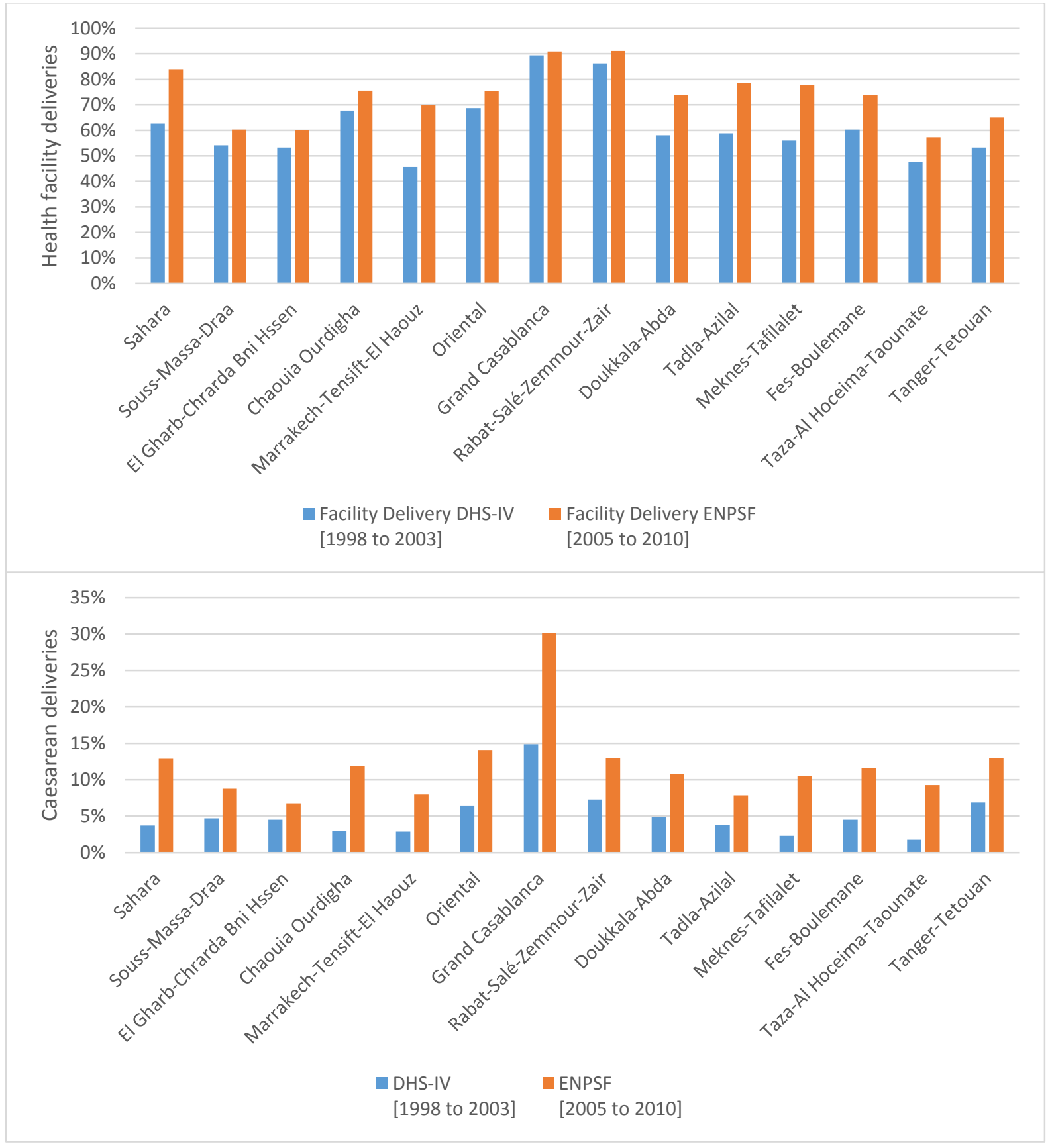


FIGURE 6: SEGMENTED REGRESSION SHOWING TRENDS IN UTILISATION OF PUBLIC-SECTOR FACILITY DELIVERY AND PUBLIC-SECTOR CAESAREANS BETWEEN THREE IMPORTANT POLICIES TO IMPROVE DELIVERY CARE

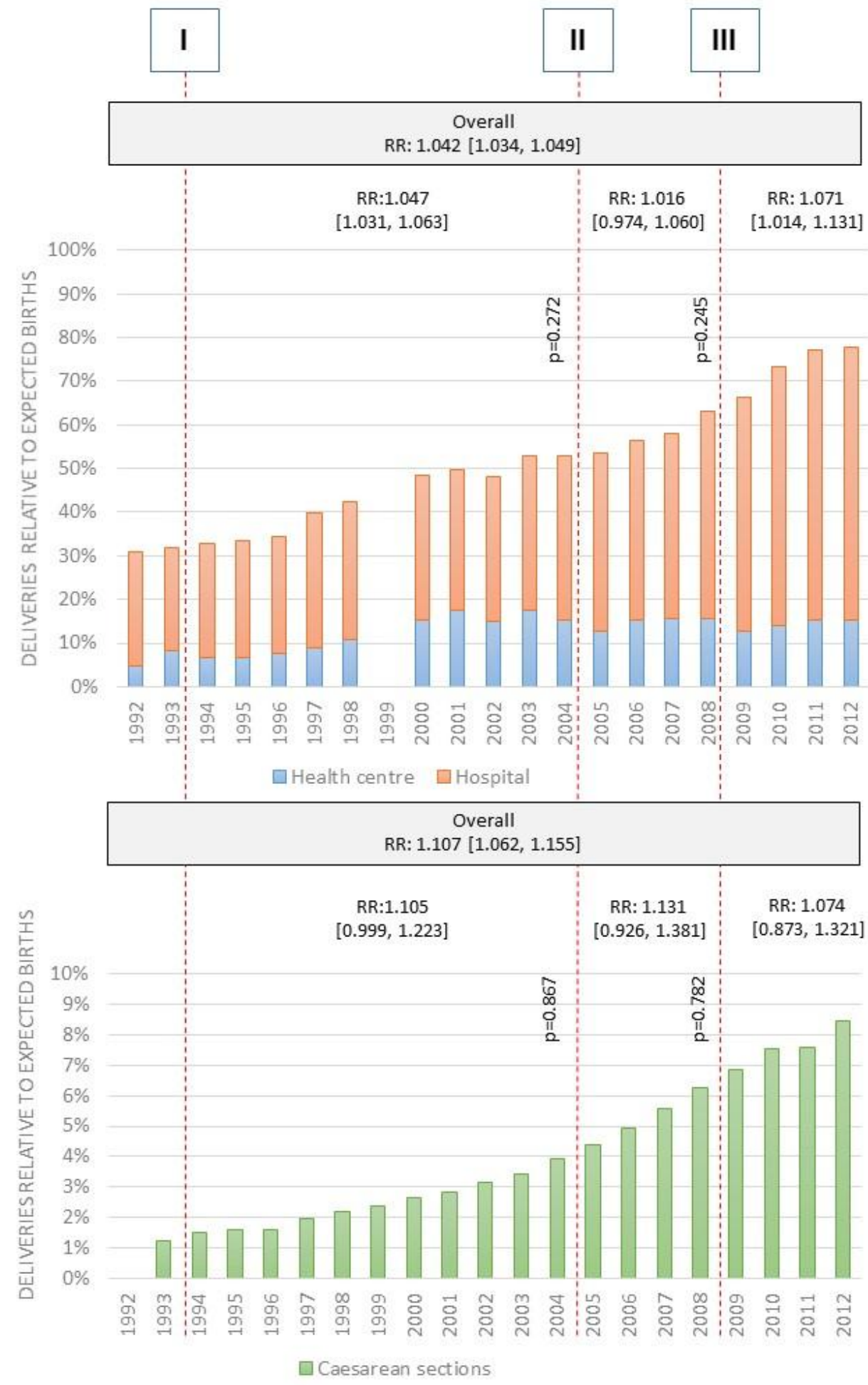

Key: I: Morocco Family Planning/Maternal and Child Health Phase V; II: mandatory health insurance (Assurance Maladie Obligatoire); III: Action Plan to Reduce Maternal Mortality. P-values test for a change in trend. 


\section{REFERENCES}

1. Campbell, O.M.R., W.J. Graham, and L.M.S. Series, Strategies for reducing maternal mortality: getting on with what works. Lancet, 2006. 368(9543): p. 1284-1299.

2. De Brouwere, V., F. Richard, and S. Witter, Access to maternal and perinatal health services: lessons from successful and less successful examples of improving access to safe delivery and care of the newborn. Trop Med Int Health, 2010. 15(8): p. 901-9.

3. Huntington, D., E. Banzon, and Z.D. Recidoro, A systems approach to improving maternal health in the Philippines. Bull World Health Organ, 2012. 90(2): p. 104-10.

4. Meessen, B., et al., Removing user fees in the health sector: a review of policy processes in six sub-Saharan African countries. Health Policy Plan, 2011. 26 Suppl 2: p. ii16-29.

5. Freedman, L.P., et al., Transforming health systems to improve the lives of women and children. Lancet, 2005. 365(9463): p. 997-1000.

6. The World Bank. World Bank Development Indicators. 2014 15th May 2014]; Available from: http://data.worldbank.org/country/morocco.

7. Kingdom of Morocco Ministry of Health and UNFPA, Reducing maternal mortality in Morocco: sharing experience and sustaining progress. 2011: Available online: http://www.who.int/pmnch/media/news/2011/20110629 morocco forum/en/.

8. World Health Organization, et al., Trends in Maternal Mortality: 1990 to 2013. Estimates by WHO, UNICEF, UNFPA, The World Bank and the United Nations Population Division 2014, World Health Organization.

9. Kassebaum, N.J., et al., Global, regional, and national levels and causes of maternal mortality during 1990-2013: a systematic analysis for the Global Burden of Disease Study 2013. The Lancet, 2014(0).

10. Temmar, F., et al., Midwives in Morocco: Seeking Recognition as Skilled Partners in WomenCentred Maternity Care. Reproductive Health Matters, 2006. 14(27): p. 83-90.

11. Johns Hopkins University Center for Communication Programs (JHU/CCP), Communicating Safe Motherhood in Morocco: The Family Planning/Maternal and Child Health Phase $V$ Project. Final Report. 2000, JHU/CCP: Baltimore.

12. El-Idrissi, D.Z., K. Miloud, and S. Belgacem, Constraints and obstacles to social health protection in the Maghreb: the cases of Algeria and Morocco. Bull World Health Organ, 2008. 86(11): p. 902-4.

13. Ruger, J.P. and D. Kress, Health financing and insurance reform in Morocco. Health Affairs, 2007. 26(4): p. 1009-16.

14. Hotchkiss, D.R., et al., The role of user charges and structural attributes of quality on the use of maternal health services in Morocco. Int J Health Plann Manage, 2005. 20(2): p. 113-35.

15. Kingdom of Morocco Ministry of Health. A propos du Régime d'Assistance Médicale (RAMED). $2014 \quad$ [cited 2014 14th May 2014]; Available from: https://www.ramed.ma/ServicesEnligne/APropos.html.

16. Ministère de la Santé du Royaume du Maroc, Circulaire sur la gratuité de l'accouchement et de la césarienne au niveau des hôpitaux publics $n^{\circ} 108$ du 11/12/2008. 2008.

17. Bennis, I. and V. De Brouwere, Fee exemption for caesarean section in Morocco. Archives of Public Health, 2012. 70(1): p. 3.

18. Ministère de la Santé Publique, Secrétariat Général - DPSI, and Service des Etudes et de I'Information Sanitaire, Enquête Nationale sur la Population et la Santé (ENPS-II) 1992. 1993: Rabat, Maroc et Columbia, Maryland, USA.

19. Ministère de la Santé du Royaume du Maroc, ORC Macro, and Ligue des États Arabes, Enquête sur la Population et la Santé Familiale (EPSF) 2003-2004. 2005: Calverton, Maryland, USA. 
20. Ministère de la Santé du Royaume du Maroc, Enquête nationale sur la population et la santé familiale (ENPSF) 2011. 2012: Rabat, Maroc.

21. Rutstein, S.O. and K. Johnson, The DHS Wealth Index, in DHS Comparative Reports No. 6. 2004, ORC Macro: Calverton, Maryland.

22. Lagarde, M., How to do (or not to do) ... Assessing the impact of a policy change with routine longitudinal data. Health Policy Plan, 2012. 27(1): p. 76-83.

23. Royaume du Maroc Ministere de la sante, Sante en chiffres 2001. 2002.

24. Royaume du Maroc Ministere de la sante, Sante en chiffre 2012. 2013.

25. UNFPA, I.C.o. Midwives; , and WHO, State of the World's Midwifery: a universal pathway. A woman's right to health. 2014.

26. World Health Organization, Monitoring emergency obstetric care: a handbook. 2009, WHO Press: Geneva.

27. Villar, J., et al., Maternal and neonatal individual risks and benefits associated with caesarean delivery: multicentre prospective study. BMJ, 2007. 335(7628): p. 1025.

28. Brugha, R. and S. Pritze-Aliassime, Promoting safe motherhood through the private sector in low- and middle-income countries. Bulletin of the World Health Organization, 2003. 81(8): p. 616-23.

29. Dzakpasu, S., T. Powell-Jackson, and O.M. Campbell, Impact of user fees on maternal health service utilization and related health outcomes: a systematic review. Health Policy Plan, 2014. 29(2): p. 137-50.

30. Abdesslam, B., Evolution of rural-urban health gaps in Morocco: 1992-2011. BMC Res Notes, 2012. 5: p. 381. 